\title{
LIGHT/TNFSF14 increases osteoclastogenesis and decreases osteoblastogenesis in multiple myeloma-bone disease
}

\author{
Giacomina Brunetti ${ }^{1, *}$, Rita Rizzi ${ }^{2, *}$, Angela Oranger ${ }^{1}$, Isabella Gigante ${ }^{1}$, \\ Giorgio Mori ${ }^{3}$, Grazia Taurino ${ }^{1}$, Teresa Mongelli ${ }^{1}$, Graziana Colaianni ${ }^{1}$, \\ Adriana Di Benedetto ${ }^{1}$, Roberto Tamma $^{1}$, Giuseppe Ingravallo ${ }^{4}$ Anna Napoli ${ }^{4}$, \\ Maria Felicia Faienza5, Anna Mestice², Paola Curci², Giorgina Specchia ${ }^{2}$, Silvia \\ Colucci ${ }^{1, *}$, Maria Grano ${ }^{1, *}$ \\ ${ }^{1}$ Department of Basic and Medical Sciences, Neurosciences and Sense Organs, section of Human Anatomy and Histology, \\ University of Bari, Bari, Italy \\ ${ }^{2}$ Department of Emergency and Organ Transplantation, Section of Hematology with Transplantation, University of Bari, \\ Bari, Italy \\ ${ }^{3}$ Department of Clinical and Experimental Medicine, University of Foggia, Foggia, Italy \\ ${ }^{4}$ Department of Emergency and Organ Transplantation, University of Bari, Bari, Italy \\ ${ }^{5}$ Department of Biomedical Sciences and Human Oncology, University of Bari, Bari, Italy \\ *These authors contributed equally to this work
}

Correspondence to:

Brunetti Giacomina, e-mail: giacomina.brunetti@uniba.it

Keywords: LIGHT/TNFSF14, multiple myeloma, bone disease, osteoclast, osteoblast

Received: August 08, 2014

Accepted: October 23, 2014

Published: December 19, 2014

\section{ABSTRACT}

LIGHT, a TNF superfamily member, is involved in T-cell homeostasis and erosive bone disease associated with rheumatoid arthritis. Herein, we investigated whether LIGHT has a role in Multiple Myeloma (MM)-bone disease. We found that LIGHT was overproduced by CD14+ monocytes, CD8+ T-cells and neutrophils of peripheral blood and bone marrow (BM) from MM-bone disease patients. We also found that LIGHT induced osteoclastogenesis and inhibited osteoblastogenesis. In cultures from healthy-donors, LIGHT induced osteoclastogenesis in RANKL-dependent and -independent manners. In the presence of a sub-optimal RANKL concentration, LIGHT and RANKL synergically stimulated osteoclast formation, through the phosphorylation of Akt, NFKB and JNK pathways. In cultures of BM samples from patients with bone disease, LIGHT inhibited the formation of CFU-F and CFU-OB as well as the expression of osteoblastic markers including collagen-I, osteocalcin and bone sialoprotein-II. LIGHT indirectly inhibited osteoblastogenesis in part through sclerostin expressed by monocytes. In conclusion, our findings for the first time provide evidence for a role of LIGHT in MM-bone disease development.

\section{INTRODUCTION}

Multiple Myeloma (MM)-bone disease, characterized by osteolytic lesions, is the most frequent clinical manifestation of symptomatic MM, being detected in 70 to $80 \%$ of patients at diagnosis and up to $90 \%$ at relapse. It increases the risk of skeletal-related events such as bone pain, pathological fractures, and spinal cord compression [1].

Osteolytic lesions result from an imbalance between increased osteoclast (OC) activity and reduced osteoblast (OB) repair [2-4]. The latter has also been related to suppressed functions of Wnt-signalling due to MM-cells through the expression of Wnt inhibitors such as dickkopf-1 (DKK1) and Sclerostin [5-11]. In addition, several cytokines belonging to tumour necrosis factor superfamily (TNFSF) have been implicated in the increased osteoclastogenesis [2, 3, 12-13]. Among these, decoy receptor 3 (DcR3) plays an important role in the $\mathrm{OC}$ formation occurring in MM-bone disease, as we previously described [14]. DcR3 is known to be also a soluble receptor of LIGHT [15] (homologous 
to Lymphotoxins exhibiting Inducible expression and competing with herpes simplex virus Glycoprotein D for herpes virus entry mediator [HVEM], a receptor expressed by $T$ lymphocytes), whose potential involvement in MM is unknown.

LIGHT is a member of TNFSF (TNFSF14) expressed on cells with an immunological role such as activated T-cells, monocytes, granulocytes, spleen cells, and immature dendritic cells $[15,16]$. As membraneanchored or secreted form, LIGHT can bind two membrane-bound TNFSF signalling receptors, HVEM and lymphotoxin beta receptor (LT $\beta$ R). HVEM is expressed on endothelial, dendritic, natural killer, T- and B-cells $[17,18]$ while LT $\beta R$ is expressed on fibroblasts, monocytes, endothelial, epithelial and stromal cells [19]. Following the interaction of LIGHT with HVEM or LT $\beta$ R, the recruitment of TNF receptor (TNFR)-associated factor-2 (TRAF2) and TRAF5 occurs, leading to gene induction through the activation of Nuclear-Factor-kappaB (NFkB) or c-Jun N-terminal kinase (JNK)/ activator protein 1 (AP-1) pathway, and finally resulting in cytokine production, cell survival or proliferation [20-23]. The LIGHT-LT $\beta R$ interaction can also lead to cell death through the recruitment of TRAF3 and subsequent activation of caspases [24, 25]. Through the interaction with HVEM, LIGHT is described as a potent T-cell co-stimulatory molecule [13, 17, 26, 27]; its constitutive expression on T-cells causes activation and expansion of these cells, favouring the development of autoimmune diseases [28, 29]. Moreover, LIGHT has been implicated in rheumatoid arthritis bone erosions $[30,31]$. To date, there are three literature reports on the contribution of LIGHT to OC formation, reaching conflicting results [30-32]. In particular, LIGHT was reported to induce in vitro differentiation of OCs from peripheral blood (PB) CD14+ monocytes of healthydonors, when co-cultured with nurse-like cells isolated from the synovium of patients with rheumatoid arthritis [30]. Conversely, no OCs differentiated from the same CD14+ monocytes cultured alone [30]. In addition, other Authors reported that, in the presence or absence of the key pro-osteoclastogenic cytokine receptor activator of nuclear factor-kappaB ligand (RANKL), LIGHT induced OC differentiation from human peripheral blood mononuclear cells (PBMCs) of healthy-donors $[31,32]$. The in vitro data regarding the LIGHT proosteoclastogenic role as well as the LIGHT high serum levels [31] found in rheumatoid arthritis patients supported a LIGHT contribution to the pathological bone resorption.

Based on the above literature data and consistently with our previous studies $[8,12,14]$, we investigated the expression of LIGHT in MM patients and the role that this cytokine may play in the osteoclastogenesis and osteoblastogenesis occurring in MM-bone disease.

\section{RESULTS}

\section{LIGHT expression in monocytes, T-cells, neutrophils and myeloma-cells from patients and controls}

By means of real-time PCR, western blotting, flow cytometry and immunohistochemistry, we assessed the expression of LIGHT in BM aspirates and biopsies from patients as well as in PB from patients and healthydonors. Using these different methods, LIGHT resulted overexpressed in 52/58 (90\%) of MM-bone disease samples, at both mRNA and protein levels; otherwise in all the other samples, its expression resulted at the lowest detectable levels by real-time PCR, and undetectable by western blotting. In particular, LIGHT expression was detected in $\mathrm{CD} 14^{+}$monocytes from all the positive samples whereas, in $50 \%$ of them, it was detected in $\mathrm{CD} 2^{+}$ T-cells and/or neutrophils, too. The above results, referred to PB samples analyzed by real-time PCR and western blotting, are shown in Figures $1 \mathrm{~A}$ and 1B, respectively. The corresponding BM samples gave overlapping results (data not shown). In Table 1, the mean values of the flow cytometry results are detailed; they are referred to $\mathrm{CD} 14^{+}$ monocytes, $\mathrm{CD} 16^{+}$neutrophils and $\mathrm{CD} 8^{+} \mathrm{T}$-cells. The latter cells were identified as the main LIGHT expressing T-cell subset in MM-bone disease samples. Representative dot plots of LIGHT cell expression are shown in Figure 1C.

By western blotting, we found low expression of LIGHT in human myeloma cell lines (HMCLs i.e. H929, RPMI-8226, U266) as well as in CD138 myeloma-cells, isolated from MM-bone disease patients. In these cells, by flow cytometry, we detected LIGHT expression at a percentage ranging from 2 to 5 (data not shown). By immunohistochemistry, we demonstrated strong expression of LIGHT in BM biopsy samples from MM-bone disease patients (Figure 1D). We did not find statistically significant difference in LIGHT serum levels among patients with MMbone disease $(207.71 \pm 26.53 \mathrm{pg} / \mathrm{ml})$ or symptomatic MM without bone disease $(179.84 \pm 20.48 \mathrm{pg} / \mathrm{ml})$ as well as in the other samples from patients with sMM $(237 \pm 89 \mathrm{pg} / \mathrm{ml})$, MGUS $(183 \pm 20.58 \mathrm{pg} / \mathrm{ml})$, nonneoplastic disease $(199 \pm 21.2 \mathrm{pg} / \mathrm{ml})$ and healthy-donors $(189.84 \pm 20.83 \mathrm{pg} / \mathrm{ml})$.

\section{Anti-LIGHT monoclonal antibody affects osteoclast formation in cultures of PBMCs and BMMNCs from MM-bone disease patients}

In culture media of PBMCs and BM mononuclear cells (BMMNCs) from MM-bone disease patients, we found higher LIGHT levels than in those from controls $(1939 \pm 220 \mathrm{pg} / \mathrm{ml}$ vs $74.7 \pm 30 \mathrm{pg} / \mathrm{ml}, p<0.001$; 


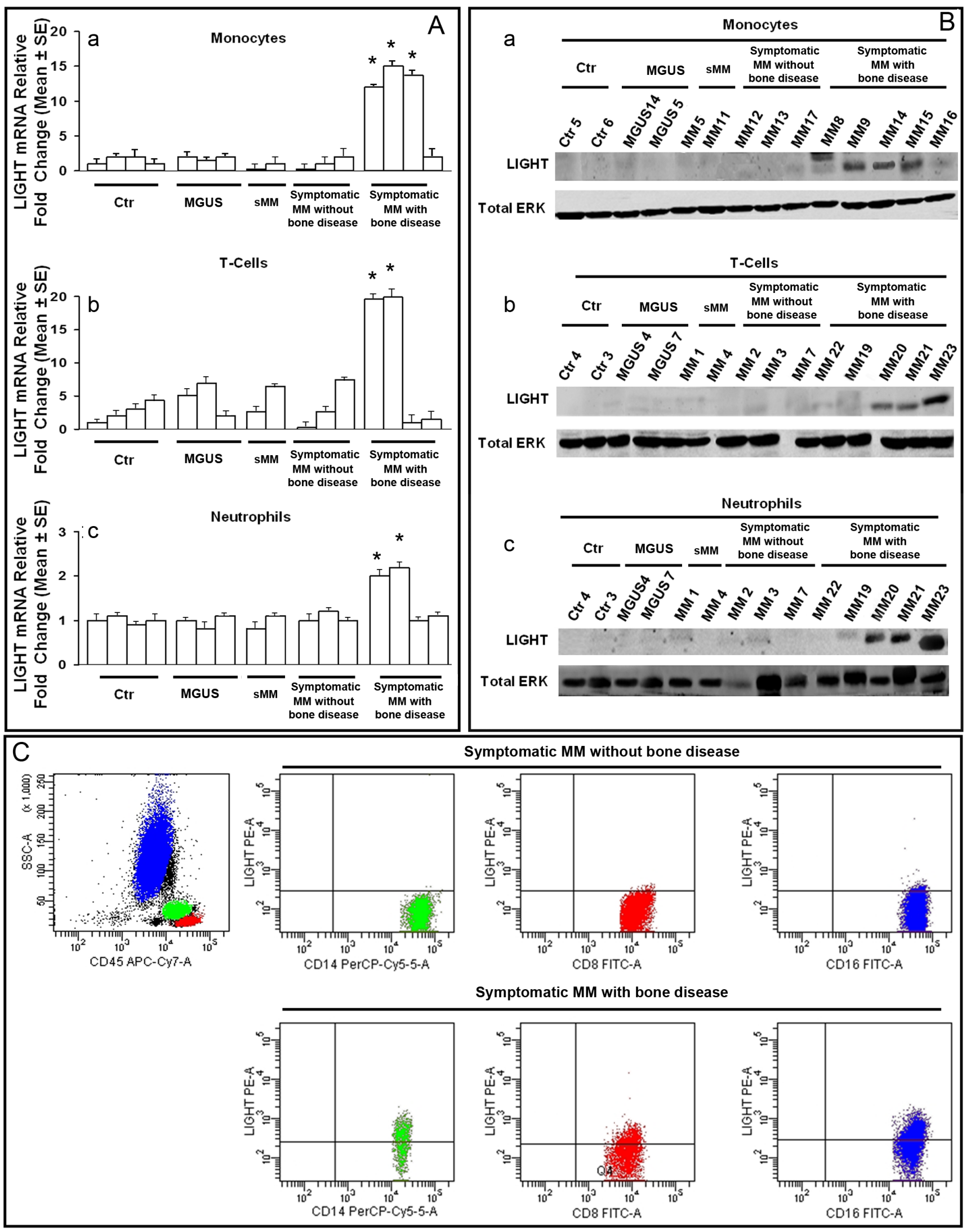

Figure 1: LIGHT expression in patients and controls. Monocytes, T-cells and neutrophils from peripheral blood of controls (ctr), MGUS, smoldering MM (sMM) and symptomatic MM patients without or with bone disease were assessed for LIGHT expression by realtime PCR (A), western blotting (B) and flow cytometry (C). LIGHT immunostaining was performed in bone marrow biopsies (D).

(Continued) 


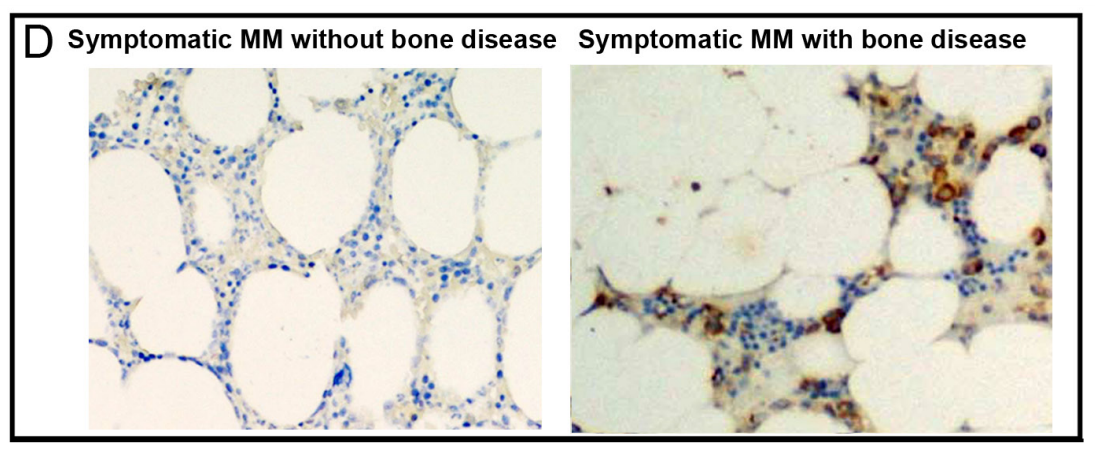

Figure 1 (Continued): The lowest mRNA levels of LIGHT were detected in monocytes (Aa), T-cells (Ab) and neutrophils (Ac) from controls, MGUS, sMM and symptomatic MM patients without bone disease. As compared with all of them, LIGHT mRNA higher levels of 11-fold $(P<0.0001)$ in monocytes (Aa), 9.2 fold $(p<0.001)$ in T-cells $(\mathrm{Ab})$ and 1.8 - fold $(p<0.01)$ in neutrophils (Ac) were detected in symptomatic MM patients with bone disease. In these latter, high levels of LIGHT protein were detected by western blotting in $90 \%$ of monocytes $(\mathrm{Ba}), 50 \%$ of T-cells $(\mathrm{Bb})$ and $50 \%$ of neutrophils $(\mathrm{Bc})$, whereas the samples of symptomatic MM patients without bone disease, sMM, MGUS and controls did not display a detectable LIGHT protein amount. Flow cytometry dot plots showed LIGHT expression on CD14+ monocytes, CD8+ T-cells and CD16+ neutrophils from a representative symptomatic MM patient without bone disease, and a symptomatic MM patient with bonedisease; in particular, LIGHT levels were higher in the former than in the latter (C). LIGHT positive immunostaining was also observed in the bone marrow biopsy from a representative symptomatic MM patient with bone-disease; conversely, LIGHT resulted negative in a symptomatic MM patient without bone-disease (D). The photomicrographs were obtained using a Nikon Eclipse E400 microscope equipped with a Nikon plan Apo 20×/0.75 DICM (Nikon, Italia), Magnification 200X.

ERK, extracellular signal-regulated kinase.

Table 1: Cytofluorimetric expression of LIGHT in CD14+ Monocytes, CD8+ T-cells and CD16+ Neutrophils from all peripheral blood and bone marrow samples.

\begin{tabular}{|l|l|l|l|l|l|l|l|l|}
\hline \multicolumn{2}{|c|}{ Ceripheral Blood } \\
\hline $\begin{array}{l}\text { Healthy- } \\
\text { donors }\end{array}$ & $\begin{array}{l}\text { Symptomatic } \\
\text { MM w/o } \\
\text { bone disease }\end{array}$ & $\begin{array}{l}\text { Symptomatic } \\
\text { MM with } \\
\text { bone disease }\end{array}$ & $\begin{array}{l}\text { Healthy- } \\
\text { donors }\end{array}$ & $\begin{array}{l}\text { Symptomatic } \\
\text { MM w/o } \\
\text { bone disease }\end{array}$ & $\begin{array}{l}\text { Symptomatic } \\
\text { MM with } \\
\text { bone disease }\end{array}$ & $\begin{array}{l}\text { Healthy- } \\
\text { donors }\end{array}$ & $\begin{array}{l}\text { Symptomatic } \\
\text { MM w/o } \\
\text { bone disease }\end{array}$ & $\begin{array}{l}\text { Symptomatic } \\
\text { MM with } \\
\text { bone disease }\end{array}$ \\
\hline $1 \pm 0.5$ & $3.6 \pm 2.8$ & $47.1 \pm 9.5^{*}$ & $1.1 \pm 0.5$ & $1 \pm 0.5$ & $8.0 \pm 5.5 \S$ & $1 \pm 0.9$ & $2 \pm 1.1$ & $40.3 \pm 17.8^{*}$ \\
\hline \multicolumn{7}{|c|}{ Bone Marrow } \\
\hline $\begin{array}{l}\text { Patients } \\
\text { with non- } \\
\text { neoplastic } \\
\text { disease }\end{array}$ & $\begin{array}{l}\text { Symptomatic } \\
\text { MM w/o } \\
\text { bone disease }\end{array}$ & $\begin{array}{l}\text { Symptomatic } \\
\text { MM with } \\
\text { bone disease }\end{array}$ & $\begin{array}{l}\text { Patients } \\
\text { with non- } \\
\text { neoplastic } \\
\text { disease }\end{array}$ & $\begin{array}{l}\text { Symptomatic } \\
\text { MM w/o } \\
\text { bone disease }\end{array}$ & $\begin{array}{l}\text { Symptomatic } \\
\text { MM with } \\
\text { bone disease }\end{array}$ & $\begin{array}{l}\text { Patients } \\
\text { with non- } \\
\text { neoplastic } \\
\text { disease }\end{array}$ & $\begin{array}{l}\text { Symptomatic } \\
\text { MM w/o } \\
\text { bone disease }\end{array}$ & $\begin{array}{l}\text { Symptomatic } \\
\text { MM with } \\
\text { bone disease }\end{array}$ \\
\hline $1.1 \pm 0.2$ & $3.5 \pm 2.3$ & $48.5 \pm 8.5^{*}$ & $0.8 \pm 0.3$ & $1 \pm 0.8$ & $12.7 \pm 7.8 \S$ & $0.9 \pm 0.3$ & $2.1 \pm 1.1$ & $21.2 \pm 9.6^{*}$ \\
\hline
\end{tabular}

$* P<0.0001 ; \S P<0.009$

$1750 \pm 352 \mathrm{pg} / \mathrm{ml}$ vs $66.2 \pm 44 \mathrm{pg} / \mathrm{ml}, p<0.01$, respectively). The culture treatment with sequential escalating doses, ranging from 0.005 to $500 \mathrm{ng} / \mathrm{ml}$, of anti-LIGHT monoclonal antibody $(\mathrm{mAb})$ induced a dose-dependent inhibition of osteoclastogenesis, quite different in cultures derived from PBMCs and BMMNCs, respectively. Indeed in PBMC cultures, 30\% inhibition of osteoclastogenesis was induced by the lowest dose $(0.005 \mathrm{ng} / \mathrm{ml})$ of the anti-LIGHT $\mathrm{mAb}$, increasing up to $50 \%$ at the highest dose of the $\mathrm{mAb}(500 \mathrm{ng} / \mathrm{ml})$ (Figure 2A). In BMMNC cultures, the highest dose $(500 \mathrm{ng} / \mathrm{ml})$ of the $\mathrm{mAb}$ was instead required to observe 


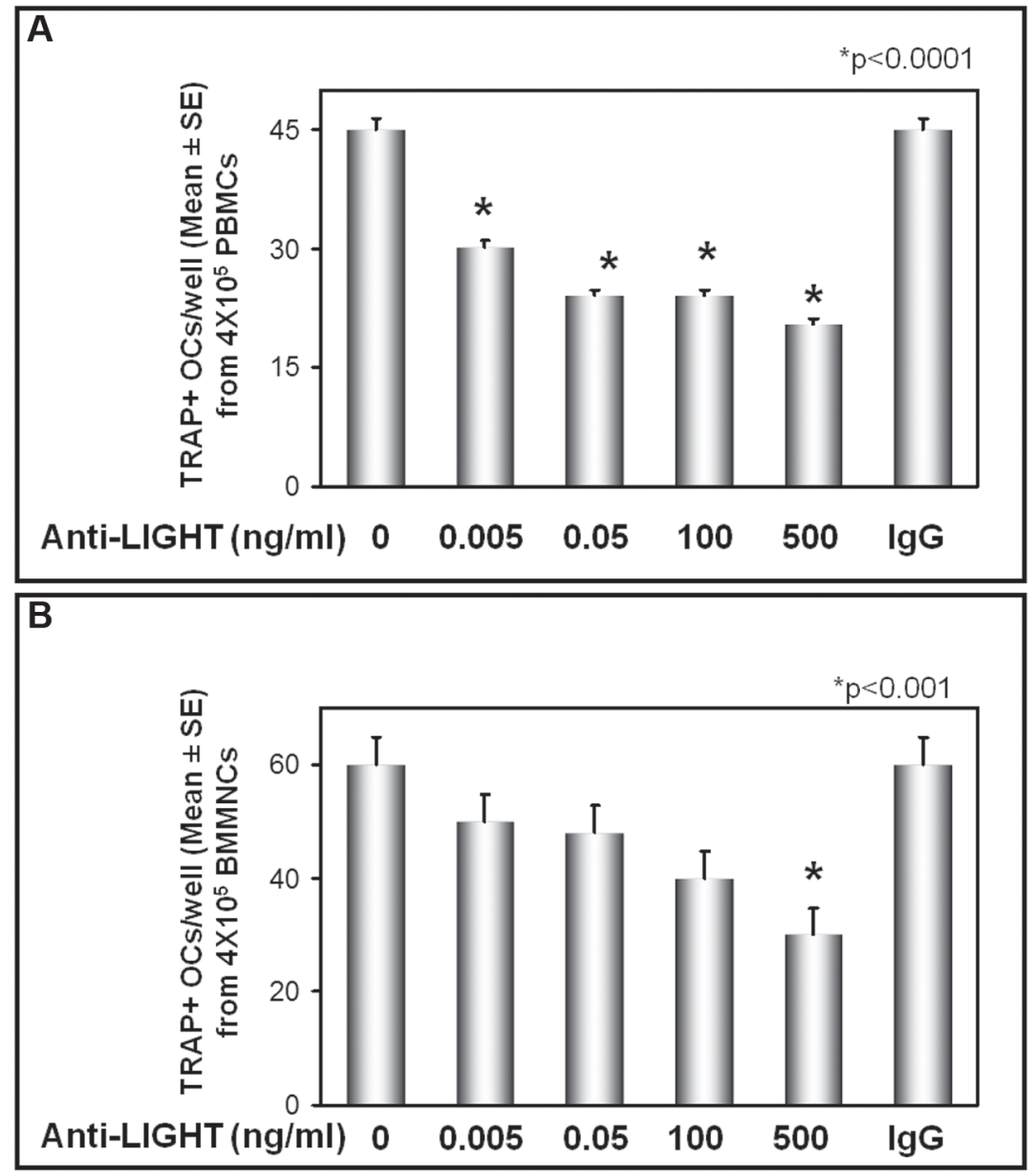

Figure 2: Anti-LIGHT mAb inhibits the osteoclast formation in cultures from MM-bone disease. Multinucleated and TRAP+ cells, differentiated from peripheral blood mononuclear cell (PBMC) (A) and bone marrow mononuclear cells (BMMNC) (B) cultures of MM-bone disease patients, were evaluated after 21 days of culture in the presence of anti-LIGHT mAb or control anti-IgG $\mathrm{mAb}$. The anti-LIGHT mAb culture treatment resulted in a dose-dependent inhibition of osteoclastogenesis, which was not affected by the control anti-IgG mAb. The number of multinucleated and TRAP+ cells, identified as OCs, are represented in the graphs as mean $\pm \mathrm{SE}$ of all experiments performed in each patient's sample.

a $50 \%$ reduction of osteoclastogenesis rate (Figure $2 \mathrm{~B}$ ). Since spontaneous osteoclastogenesis in vitro occurred only in MM-bone disease patients, we did not test the effect of anti-LIGHT mAb in PBMCs and BMMNCs of MGUS and sMM patients.

\section{Anti-LIGHT mAb affects osteoblast differentiation in cultures of BMNCs from MM-bone disease patients}

To investigate whether LIGHT could be implicated in the impaired OB differentiation occurring in MM-bone disease, we performed long-term cultures (allowing cell to cell contacts) of patients' bone marrow nuclear cells (BMNCs), in the absence or presence of the anti-LIGHT $\mathrm{mAb}(100$ or $200 \mathrm{ng} / \mathrm{ml})$. CFU-F and CFU-OB formation was referred to the early and the late phase of $\mathrm{OB}$ differentiation, respectively. In the absence of anti-LIGHT
$\mathrm{mAb}$, the formation rate of both the CFU-F and CFU-OB was low (Figure $3 \mathrm{~A}-\mathrm{B}$ ). Otherwise, in the presence of antiLIGHT $\mathrm{mAb}$ at both the concentrations, a dose-dependent increase of CFU-F and CFU-OB formation occurred (Figure $3 \mathrm{~A}, \mathrm{~B}$ ). The anti-LIGHT mAb seems to exert the above effects through the induction of BM stromal fraction proliferation, as shown with the 5'-Bromo-2'-deoxyuridine (BrdU) test. Indeed, there was a dose-dependent increase of BrdU incorporation by the BMNCs, cultured in the presence of 100 or $200 \mathrm{ng} / \mathrm{ml}$ anti-LIGHT $\mathrm{mAb}$ (Figure 3C). Thereafter by flow cytometry, we identified the CD45+ cells as the source of LIGHT in CFU-F and CFU-OB cultures from MM-bone disease patients (data not shown). Additionally, the purified BM stromal cell fraction (BMSCs), cultured in osteogenic medium, did not express LIGHT mRNA in contrast with the positive control, consisting of LIGHT expressing T-cells from MM-bone disease patients, as shown in Figure 3D. 

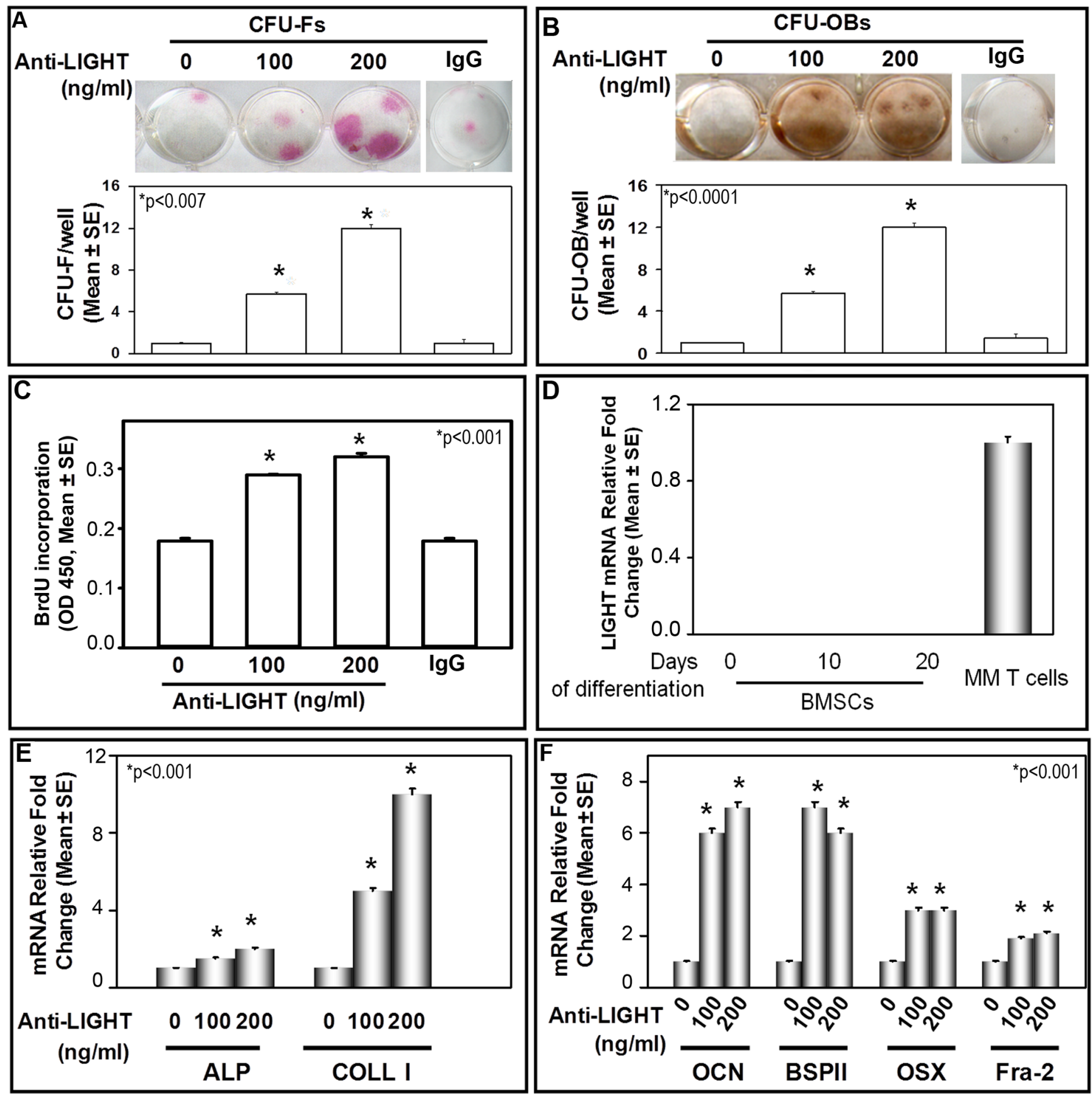

Figure 3: Anti-LIGHT mAb effect on CFU-F and CFU-OB formation in BMNC cultures of MM-bone disease patients. (A) CFU-F and (B) CFU-OB detected in bone marrow nuclear cell (BMNC) cultures from MM-bone disease patients, in the absence (0) or presence of 100 or $200 \mathrm{ng} / \mathrm{ml}$ anti-LIGHT neutralizing mAb. The results were compared to those obtained from untreated BMNC cultures. Anti-LIGHT mAb significantly increased CFU-F (A) and CFU-OB (B) formation in a dose-dependent manner. No effect was detected in the presence of a control anti-IgG mAb. The graphs represent the mean number of CFU-F/well or CFU-OB/well $\pm \mathrm{SE}$ of 6 independent experiments performed in triplicate. (C) 5-bromo-2-deoxyuridine (BrdU) incorporation evaluated in BMNC cultures from MM-bone disease patients, treated or not with 100 and $200 \mathrm{ng} / \mathrm{ml}$ anti-LIGHT mAb, which positively affected cell proliferation. The graph represents BrdU incorporation evaluated in 6 experiments performed in quadruplicate. (D) Purified bone marrow stromal cells (BMSCs) cultured in osteogenic medium for 0, 10 and 20 days did not express LIGHT mRNA. The positive control was represented by T-cells from MM-bone disease patients. (E) Anti-LIGHT mAb increased the expression at mRNA level of Alkaline Phosphatase (ALP) and Collagen-I (COLL-I). (F) Anti-LIGHT mAb increased the expression at mRNA level of osteocalcin (OCN), bone sialoprotein II (BSP II), Osterix (OSX) and Fra-2. The graphs show 6 real-time PCR experiments performed in triplicate. 
By real-time PCR in CFU-F cultures from those patients, we found a low expression of ALP and COLL-I, strongly increased after treatment with $100 \mathrm{ng} / \mathrm{ml}$ or $200 \mathrm{ng} / \mathrm{ml}$ antiLIGHT mAb (Figure 3E). Further in CFU-OB untreated cultures, we detected a low expression of BSPII and OCN (matrix glycoproteins typically expressed during the late phase of OB differentiation) as well as of Fra-2 and OSX (transcription factors), as represented in Figure 3F. In the presence of 100 or $200 \mathrm{ng} / \mathrm{ml}$ anti-LIGHT mAb, we detected significantly increased mRNA levels of the above molecules. The control anti-IgG mAb did not affect such mRNA expression (data not shown).

\section{LIGHT induces osteoclast differentiation from healthy-donor PBMCs and purified CD14+ monocytes}

We investigated the effect of LIGHT on OC differentiation in cultures of unfractionated PBMCs or purified CD14+ monocytes from healthy-donors. In these cultures, the monocyte precursors differentiate into multinucleated TRAP+ OCs within 18-21 days, only in the presence of MCSF $(25 \mathrm{ng} / \mathrm{ml})$ and RANKL $(30 \mathrm{ng} / \mathrm{ml})$. In PBMC cultures treated with MCSF and LIGHT at increasing concentrations $(5,20$ or $50 \mathrm{ng} / \mathrm{ml})$, a dose-dependent formation of multinucleated and TRAP+ cells was also seen. In the presence of LIGHT, however, the formation of a lower number of OCs than in RANKL $(30 \mathrm{ng} / \mathrm{ml})$ treated cultures appeared. Moreover, in PBMC cultures treated with both LIGHT (at the concentrations of 5,20 or $50 \mathrm{ng} / \mathrm{ml}$ ) and RANKL (at a sub-optimal dose of $20 \mathrm{ng} / \mathrm{ml}$ ), active osteoclastogenesis occurred. Herein, the rate of OC formation was significantly higher than in the presence of either LIGHT or RANKL alone (Figure 4A). The OCs formed in the presence of LIGHT (with or without RANKL) were functional, as demonstrated by their ability in resorbing mineralized matrix. In particular, in the PBMC cultures, OC resorption area increased proportionally to the escalating concentrations of LIGHT; this aspect was more evident in cultures treated with both LIGHT and RANKL, as represented in Figure 4B. The same results, referred
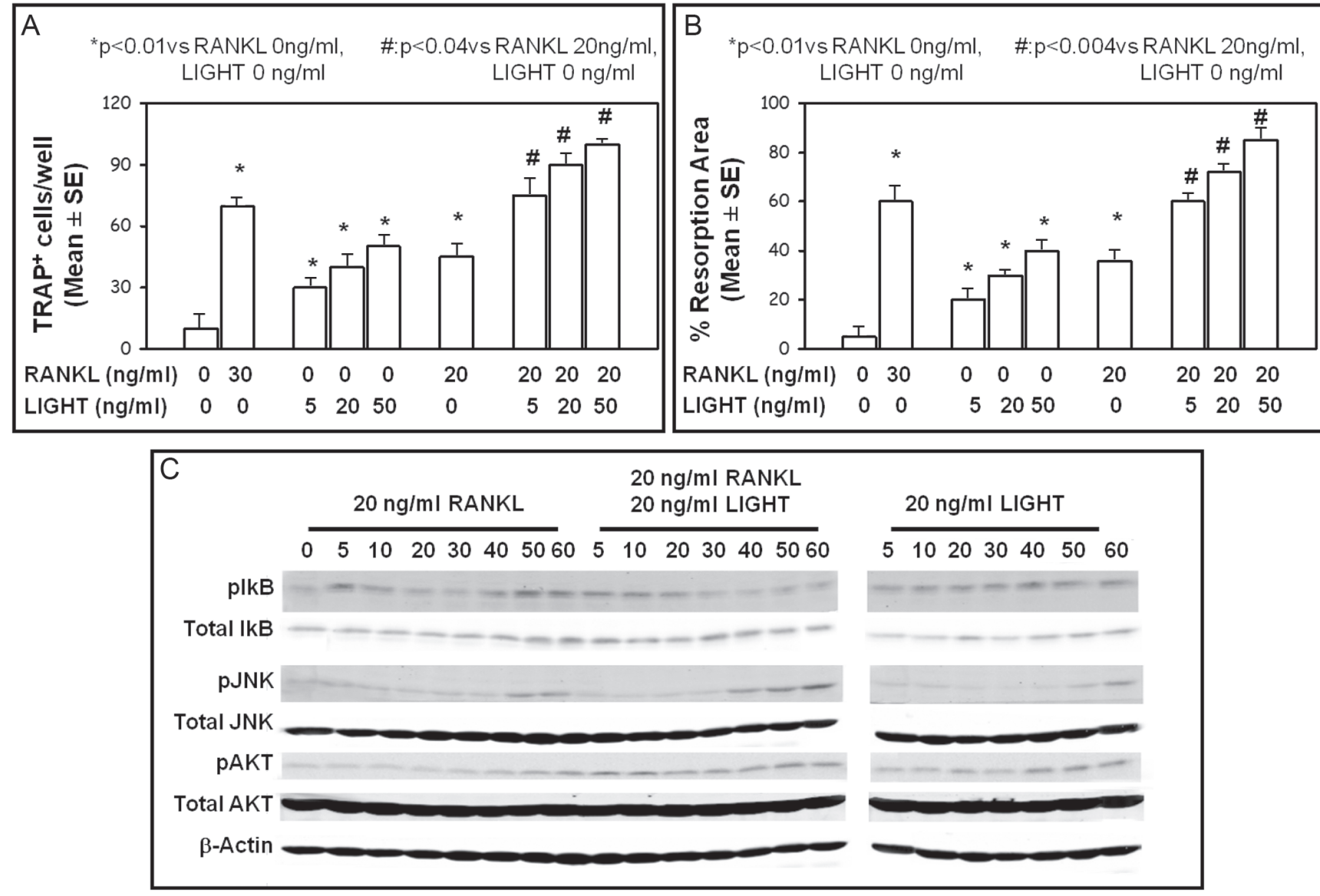

Figure 4: LIGHT pro-osteoclastogenic effect. LIGHT treatment of cultures of PBMCs from healthy-donors resulted in dosedependent increase of OC formation (A) and resorption activity (B). These effects were more evident after culture treatment with both RANKL and LIGHT. TRAP+ OC number (A), and resorption area percentage (B) were assessed, and the results represented the mean \pm SE of 12 independent experiments. (C) Western blot analysis of phosphorylated AKT, JNK, IKB in pre-osteoclasts from healthy-donors incubated with RANKL, RANKL + LIGHT, or LIGHT over a time course (0 to $60 \mathrm{~min})$. 
to both the number of formed OCs and the resorption area, were obtained in cultures from purified CD14+ monocytes (data not shown).

To further investigate LIGHT effect on OC formation in the presence or absence of RANKL, we analyzed both the intracellular signal and the expression of HVEM and LT $\beta R$ in pre-osteoclasts treated with RANKL and/or LIGHT. RANKL as well as LIGHT induced the phosphorylation of IKBa (at 5-10 min for RANKL, and longer for LIGHT), JNK (maximum at 50-60 $\mathrm{min}$ ) and Akt (maximum at 40-60 min) (Figure 4C). Otherwise, the simultaneous treatment with LIGHT and RANKL resulted in early and/or prolonged phosphorylation of Akt (persisting for all the investigated times), ІкBa (maximum at 5-20 min) and JNK (maximum at 40-60 min) (Figure 4C). By contrast, the expression of HVEM and LT $\beta$ R did not significantly change after the pre- osteoclast exposure to RANKL, LIGHT or both (data not shown).

\section{LIGHT effect on osteoblastogenesis}

We investigated the effect of LIGHT on osteoblastogenesis by assessment of CFU-F and CFU-OB formation, occurring in cultures of BMNCs from patients without MM-bone disease (including symptomatic MM, sMM, MGUS, non-neoplastic disease), in the presence or absence of 100 or $200 \mathrm{ng} / \mathrm{ml}$ LIGHT. In BMNC cultures, we found that LIGHT treatment strongly inhibited both CFU-F (Figure 5A) and CFU-OB (Figure 5B) formation in a dose-dependent manner. Moreover, we found that LIGHT impaired the expression of osteogenic markers of both early and late phase of $\mathrm{OB}$ differentiation. In the early phase, LIGHT particularly inhibited the expression of Alkaline Phosphatase (ALP), and Collagen-I (COLL-I), Fra-2 and Jun-D (Figure 5C); differently in the late phase, it decreased mRNA levels of osteopontin (OPN), bone sialoprotein II (BSP II), osteocalcin (OCN) and Osterix (OSX) (Figure 5D).
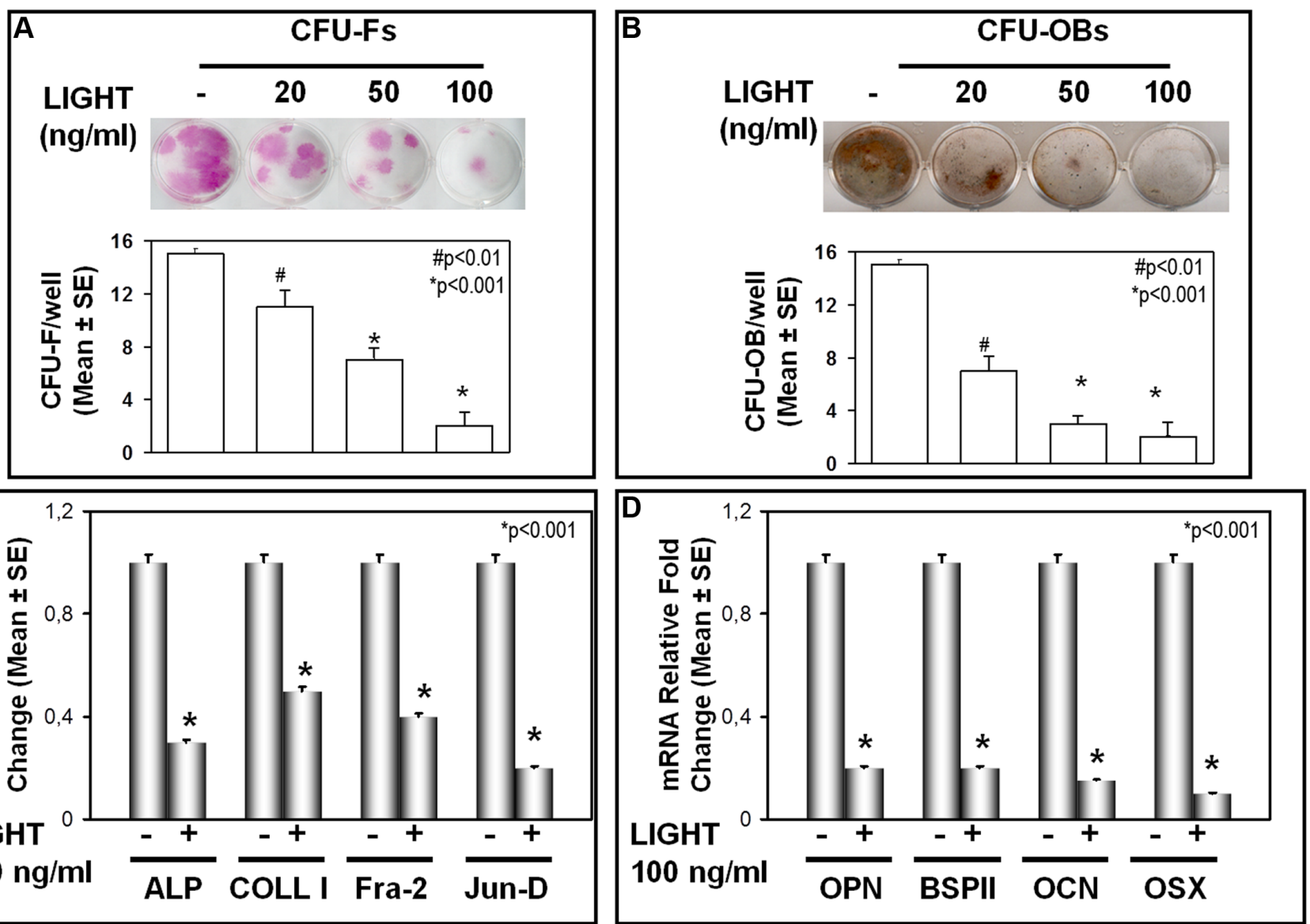

Figure 5: LIGHT effect on CFU-F and CFU-OB formation. (A) CFU-F and (B) CFU-OB formation were detected in BMNC cultures from MGUS and non-neoplastic patients in the absence (0) or presence of 20, 50 or $100 \mathrm{ng} / \mathrm{ml}$ LIGHT. The results were compared to those obtained from parallel untreated cultures. LIGHT significantly inhibited both CFU-F (A) and CFU-OB (B) formation in a dosedependent manner. The graphs represent the mean number of CFU-F/well or CFU-OB/well $\pm \mathrm{SE}$ of 6 independent experiments performed in triplicate. (C) LIGHT inhibited the expression at mRNA level of Alkaline Phosphatase (ALP), Collagen-I (COLL-I), Fra-2 and Jun-D. (D) LIGHT significantly inhibited the expression at mRNA level of osteopontin (OPN), bone sialoprotein II (BSP II), osteocalcin (OSC) and Osterix (OSX). The graphs show 6 real-time PCR experiments performed in triplicate. 
These experiments, however, did not indicate whether LIGHT exerts a direct or indirect effect on osteoblastogenesis, because BMNCs include mesenchymal (i.e. stromal) cells differentiating into OBs and hematopoietic cells. On the other hand, the latter cells are known to express LIGHT receptors [17-19], and to secrete soluble factors positively affecting CFU-F and CFU-OB survival and proliferation [33]. To address this issue, we performed cultures of either bone marrow stromal cells (BMSCs) or mesenchymal stem cells (MSCs) from dental follicle, which allowed to exclude hematopoietic cell involvement in LIGHT-mediated osteoblastogenesis; both BMSCs and MSCs are indeed lacking in hematopoietic cell fraction. The BMSCs as well as the MSCs were cultured in osteogenic medium and in the presence or absence of LIGHT; MSCs were co-cultured with monocytes and/or T-cells, too. LIGHT resulted to affect osteoblastogenesis neither in the cultures of BMSCs (data not shown) nor in those of MSCs alone (Figure 6A), suggesting that it is not able to exert a direct effect on osteoblastogenesis. Conversely, in the co-cultures of MSCs either with monocytes plus T-cells or with monocytes alone, we detected a significant LIGHT impairment of osteoblastogenesis (Figure 6A). Indeed in

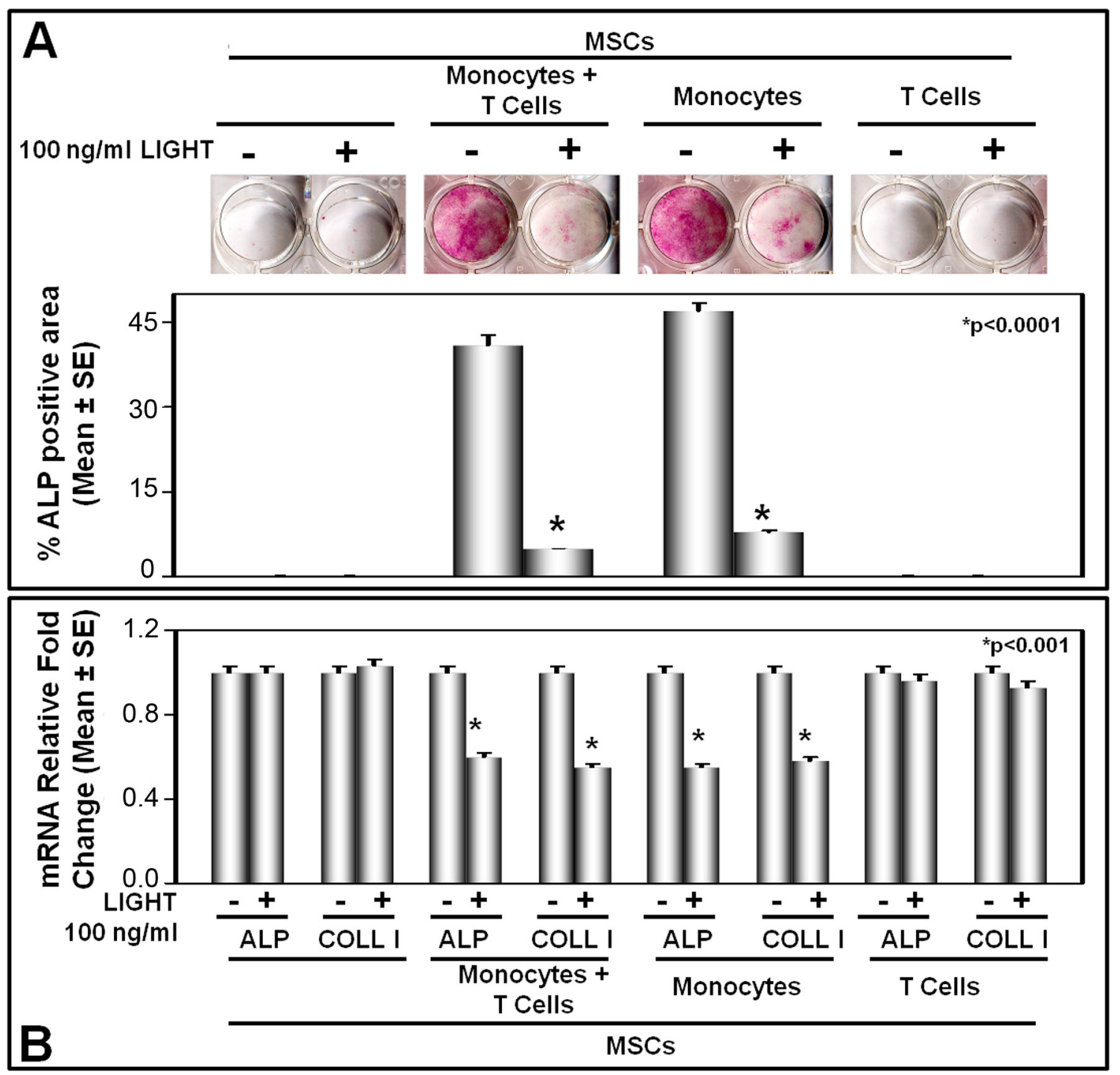

Figure 6: LIGHT effect on osteoblastogenesis in co-cultures of mesenchymal stem cells and monocytes with or without T-cells. (A) For 8 days in osteogenic medium and in the presence or absence of $100 \mathrm{ng} / \mathrm{ml}$ LIGHT, mesenchymal stem cells (MSCs) were cultured alone or co-cultured with monocytes + T-cells, monocytes, or T-cells, respectively. In co-cultures of MSCs with either monocytes + T-cells or monocytes alone, LIGHT significantly inhibited the differentiation of Alkaline Phosphatase positive (ALP+) osteoblasts. The graphs represent the mean percentage of ALP positive area/well \pm SE of 5 independent experiments performed in triplicate. (B) In the same conditions, LIGHT inhibited the expression, at mRNA level, of Alkaline Phosphatase (ALP) and Collagen-I (COLL-I) in co-cultures of MSCs with monocytes + T-cells, or monocytes alone, respectively.

(Continued) 

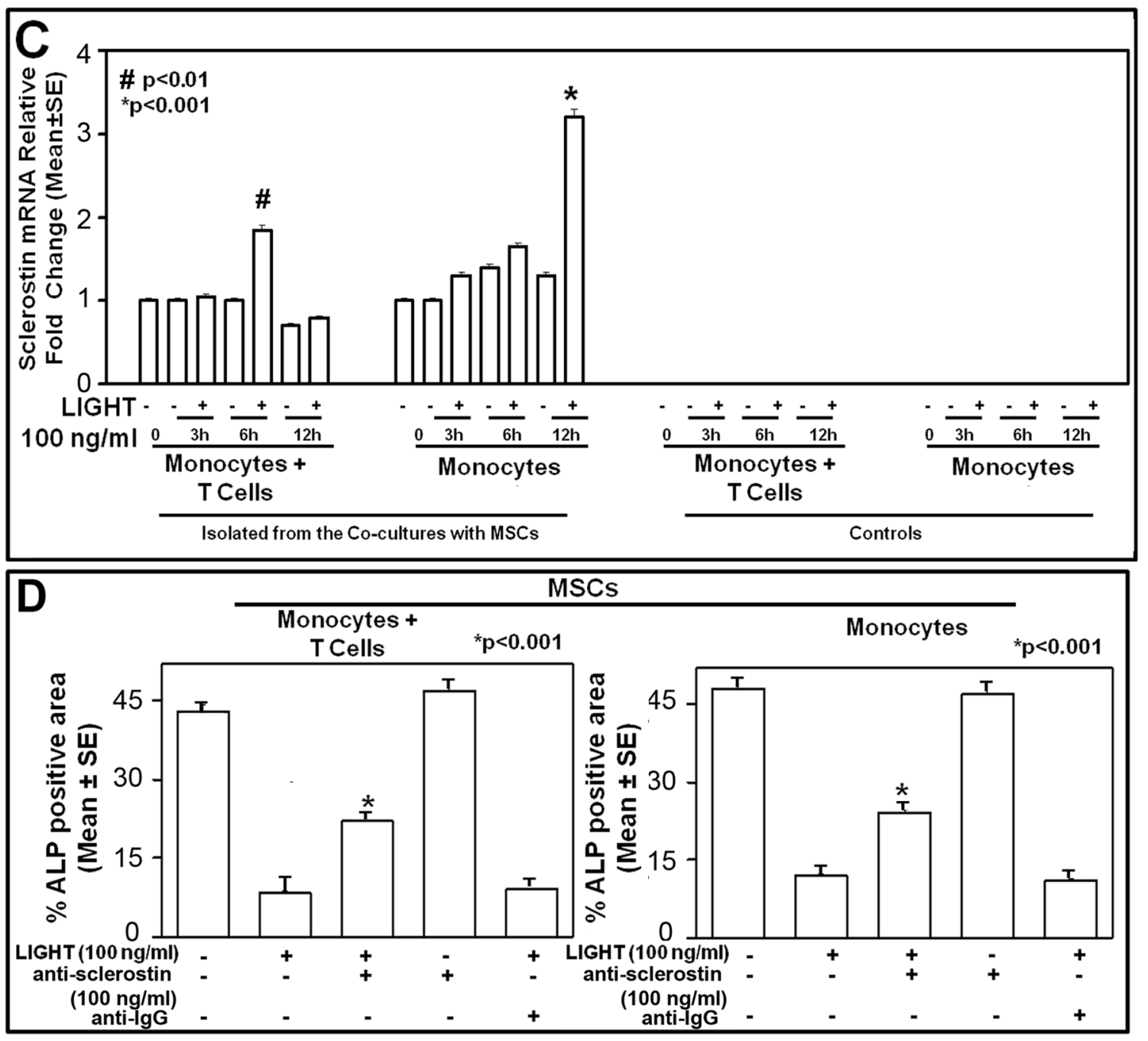

Figure 6 (Continued): (C) In the absence or presence of $100 \mathrm{ng} / \mathrm{ml}$ LIGHT over a time course [0 to 12 hours (h)], cultures of monocytes + T-cells or monocytes alone as well as co-cultures of MSCs with monocytes + T-cells, or monocytes alone were performed. Thereby, sclerostin expression was evaluated in the cell extracts from each co-culture consisting of monocytes + T-cells or monocytes alone. The results showed a significant sclerostin up-regulation occurring at 6 hours in the co-coltures of MSCs with monocytes + T-cells, and at 12 hours in those of MSCs with monocytes alone. (D) For 8 days in osteogenic medium and in the presence or absence of $100 \mathrm{ng} / \mathrm{ml} \mathrm{LIGHT}$ and $/ \mathrm{or} 100 \mathrm{ng} / \mathrm{ml}$ anti-sclerostin $\mathrm{mAb}$, mesenchymal stem cells (MSCs) were cultured alone and co-cultured with monocytes + T-cells or monocytes, respectively. By treating the above described co-cultures simultaneously with LIGHT and a neutralizing anti-sclerostin mAb, LIGHT inhibitory effect on the differentiation of ALP+ osteoblasts was partially reverted.

LIGHT treated co-cultures, we found significantly reduced ALP positive surface/well (Figure 6A) as well as lower levels of ALP and COLL-I mRNA than in the untreated co-cultures (Figure 6B). Albeit slightly, LIGHT inhibitory effect on osteoblastogenesis was more evident in the co-cultures of MSCs with monocytes plus T-cells than in those with monocytes alone. Finally, no LIGHT effect on osteoblastogenesis was detected in the co-cultures between MSCs and T-cells (Figure 6A).

\section{High Sclerostin levels were associated to LIGHT inhibitory effect on osteoblastogenesis}

In order to investigate the mechanism of LIGHT inhibitory effect on osteoblastogenesis, we treated the co-cultures of MSCs with monocytes alone or monocytes plus T-cells with $100 \mathrm{ng} / \mathrm{ml}$ LIGHT for 3, 6 and 12 hours, after over-night MSC adhesion. At each time, cell extracts from isolated monocytes, and from monocytes 
plus T-cells were obtained after purity assessment (99\% $\mathrm{CD} 45^{+}$) by flow cytometry. The above cell extracts were then evaluated for the expression of genes involved in osteoblastogenesis inhibition such as TNF $\alpha$, DKK1 and sclerostin. Among these, statistically significant results were obtained only for sclerostin, which is known to be produced by osteocytes [34]. After $6 \mathrm{~h}$ LIGHT treatment, increased levels of sclerostin mRNA were detected in the monocyte plus T-cell extracts; otherwise in the monocyte extracts, sclerostin expression increased to a statistically significant level after $12 \mathrm{~h}$ LIGHT treatment, as depicted in Figure 6C. Therefore, the effect of LIGHT on sclerostin expression was stronger in the RNA extracts from monocytes than in those from monocytes plus T-cells. In the cell extracts from the parallel cultures without MSCs, no sclerostin mRNA expression was instead detected (Figure 6C). Interestingly, the treatment of the above co-cultures with both LIGHT and a neutralizing antisclerostin $\mathrm{mAb}$, partially reverted the sclerostin inhibitory effect on osteoblastogenesis (Figure 6D).

\section{DISCUSSION}

The results of the present study highlighted the high expression of LIGHT in PB and BM samples from the large majority of MM-bone disease patients at diagnosis, in whom LIGHT was demonstrated to be involved in both increased osteoclastogenesis and decreased osteoblastogenesis.

Firstly, we detected high LIGHT expression in CD14+ monocytes, CD8+ T-cells and CD16+ neutrophils from $\mathrm{PB}$ and $\mathrm{BM}$ of newly diagnosed patients with MMbone disease. Conversely, we found a low or undetectable expression of LIGHT in the other samples from patients affected by symptomatic MM without bone disease, sMM, MGUS, non-neoplastic disease and in healthy-donors.

In the literature, LIGHT was reported in rheumatoid arthritis erosive bone-disease as expressed by synovial CD4+ T-cells [35] as well as PB and synovial fluid CD14+ monocytes and CD20+ B-cells [36].

Secondly, by means of an in vitro osteoclastogenesis model consisting of PBMC and BMMNC cultures from MM-bone disease patients, we demonstrated that LIGHT exerts a pro-osteoclastogenic effect. Indeed, the neutralizing anti-LIGHT $\mathrm{mAb}$ induced a dose-dependent inhibition of osteoclastogenesis spontaneously occurring in both the above cultures derived from MM-bone disease patients. We observed, however, that in PBMC cultures lower doses of the $\mathrm{mAb}$ inhibited $\mathrm{OC}$ formation, compared with those required to obtain the same effect in the parallel BMMNC cultures. Consistently with the literature including our previous reports $[2,12,14,37]$, these results support the involvement of various cytokines, figuring out the occurrence of alternate or additional pathways concerning OC formation and activity. Additionally, it must be also considered the greater complexity of the cultures derived from BM compared to those from $\mathrm{PB}$ $[37,38]$.

Furthermore, we investigated LIGHT proosteoclastogenic effect using cultures of PBMCs or CD14+ monocytes from the healthy-donors, where LIGHT dose-dependently increased the OC formation rate. This finding was amplified in the presence of a suboptimal concentration of RANKL, indicating that LIGHT pro-osteoclastogenic effect occurs both in a RANKLdependent and -independent way, as also reported in the literature [31, 32]. Conversely, other Authors did not describe a LIGHT pro-osteoclastogenic effect from CD14+ monocyte precursors [30]; these conflicting results might be explained by different culture conditions, such as the number of monocytes plated by them, which was lower than ours [30]. In addition, we found that LIGHT pro-osteoclastogenic effect is related to phosphorylation of the intracellular signaling, typically activated by RANKL during osteoclastogenesis and including IkB, AKT and JNK pathways [39, 40]. However, other Authors [32] described the phosphorylation of both IkB and AKT, following LIGHT stimulation of RAW264 and HL60, and a low rate of phosphorylation of JNK in HL60; both these murine monocyte cell lines are capable of differentiating into OCs under appropriate conditions [31, 41]. The absence or the low rate of JNK phosphorylation might be related to the use of cell lines rather than primary human cells [32]. We detected early and sustained phosphorylation of IkB, AKT and JNK in the cultures treated with both LIGHT and RANKL, whose synergic pro-osteoclastogenic effect resulted herein highlighted. It seems to resemble a mechanism possibly underlying the in vivo bone destruction occurring in MM-bone disease, where RANKL is known to play a pivotal role $[2,12,13,42]$.

Thirdly, the results of the present study showed for the first time that LIGHT also affects OB differentiation in BMNC cultures derived from MM-bone disease patients; in which, the osteoblastogenesis indeed resulted significantly improved by the addition of anti-LIGHT $\mathrm{mAb}$. Moreover in BMNC cultures from patients without bone disease, we demonstrated that the addition of LIGHT inhibited osteoblastogenesis. Since BMNCs include mesenchymal cell fraction and CD45+ cells, we could not argue whether LIGHT induces the osteoblastogenesis impairment through a direct or indirect effect. Thus, we carried on with our study evaluating OB differentiation from BMSCs of patients with or without bone disease, in the presence or absence of LIGHT. In addition, we assessed the effects of LIGHT on MSCs isolated from dental follicle, cultured alone or co-cultured with monocytes and/or T-cells. This model was suitable for our purposes since MSCs are known to be immunologically privileged cells [43]. Since no effect of LIGHT on OB differentiation was detected either in cultures of BMSCs 
or in those of MSCs alone, the event of a LIGHT direct effect could be excluded. On the contrary, the results we detected in the co-cultures of MSCs with monocytes alone and/or T-cells pointed out a LIGHT indirect effect, to some extent occurring through the release of sclerostin by monocytes. Sclerostin is indeed a key inhibitor of OB differentiation, known to be produced by osteocytes [34], whereas there are no literature data concerning its expression by monocytes. Some Authors, however, described sclerostin expression within the hematopoietic islands of embryo livers and by OCs, which are known to be derived from the fusion of monocyte precursors $[44,45]$. Therefore, we could argue that sclerostin may be expressed by monocytes under particular conditions. There are numerous literature reports on monocyte involvement in osteoblastogenesis [46-48]; in particular, bone resident macrophages have been recognized as critical regulators of bone homeostasis and repair in a murine tibia injury model [48]. The increase of cytokines such as IL-1 $\beta$, IL-6, IL-10 and TNFa was described as following the MSC-monocyte contact [49-53]; no role was, however, recognized to these cytokines in the enhanced monocyte-induced osteogenesis. In studies using MG-63 osteoblastic cell line or calvarial OBs, IL-6 has been described as involved in the direct promotion of osteogenic differentiation [54, 55]. More recently, monocytes have been reported as regulating the osteogenic differentiation of MSCs through cell-contact mechanisms involving Oncostatin-M in monocytes, and STAT-3 signaling in MSCs [56].

In conclusion, the results of the present study show for the first time high expression of LIGHT by monocytes, T-cells and neutrophils from symptomatic MM patients with bone disease. Further, our results show that LIGHT seems to be implicated in the development of MM-bone disease through a direct pro-osteoclastogenic effect and an indirect induction of OB suppression. Based on these findings, LIGHT provides a potential target for novel therapeutic strategies.

\section{PATIENTS AND METHODS}

\section{Patients}

$\mathrm{PB}$, bone marrow (BM) aspirates and biopsies were obtained from 80 patients newly diagnosed as having symptomatic MM (58 of them with, and 22 without related bone disease), 16 with smoldering MM (sMM), and 35 with monoclonal gammopathy of undetermined significance (MGUS). The control samples included PB and BM from 10 patients with non-neoplastic disease without skeletal involvement, and PB from 30 healthy volunteer blood donors (healthy-donors), age and sex matching with the patients.

The patient characteristics are reported in Table 2 . All patients underwent skeletal X-ray, and some of them also required magnetic resonance imaging or computerized tomography to assess symptomatic bone sites, pathological fractures, cord compression or tumour mass. Patient diagnoses were performed according to the International Myeloma Working Group's (IMWG) criteria [1, 57], and symptomatic MM was also classified according to the International Staging System (ISS) [58]. Patients and controls gave their informed consent to the study performed according to the Declaration of Helsinki, and approved by Bari University Hospital Ethical Committee.

\section{Cells and cell cultures}

\section{Human myeloma cell lines (HMCLs) and CD138+ cells}

HMCLs (H929, RPMI-8226, U266) were cultured in RPMI-1640 medium supplemented with 10\% fetal bovine serum (FBS; Life Technologies, Milan, Italy). Plasma cells, identified as CD138+ cells, were isolated from BM aspirates [8]. RNA or proteins were extracted from HMCLs and fresh CD138+ cells to evaluate LIGHT expression.

\section{Bone marrow and peripheral blood cells}

Buffy coat BM nuclear cells (BMNCs) and PB mononuclear cells (PBMCs), isolated by Histopaque 1077 density gradient (Sigma, St Louis, MO), were plated. Thereby, BM stromal cells (BMSCs) and BM mononuclear cells (BMMNCs) were obtained from BMNC adherent and non-adherent fractions, respectively. BMMNC and PBMC cultures were performed to investigate osteoclastogenesis, whereas BMNCs and BMSCs were cultured to investigate osteoblastogenesis.

\section{Mesenchymal stem cells (MSCs), bone marrow and peripheral blood cells}

MSCs, isolated as previously described [59], were used for osteoblastogenesis experiments.

\section{CD14+ monocyte, CD2+ T-cell and neutrophil isolation}

From PBMCs and BMNCs, CD14+ and CD2+ cells were purified by immunomagnetic selection (Miltenyi Biotec $\mathrm{GmbH}$, Bergisch Gladbach, Germany), according to the manufacturer's instruction. Neutrophils were isolated as previously described [60]. Only samples with a purity $>98 \%$, checked by flow cytometry, were considered. RNA and proteins were extracted from purified CD14+ monocytes, CD2+ T-cells and neutrophils to evaluate LIGHT expression. CD14+ monocytes were also used in osteoclastogenesis experiments.

\section{Osteoclastogenesis}

To investigate LIGHT-dependent OC formation, BMMNCs and PBMCs from MM-bone disease patients were plated at $1.5 \times 10^{6} \mathrm{cell} / \mathrm{cm}^{2}$ in a-Minimal Essential Medium (a-MEM, Life Technologies), 
Table 2: Characteristics of patients and controls.

\begin{tabular}{|c|c|c|c|c|c|c|}
\hline \multirow[t]{2}{*}{ Parameters } & \multicolumn{2}{|c|}{ Symptomatic MM at diagnosis } & \multirow{2}{*}{$\begin{array}{l}\text { Smoldering } \\
\text { MM }\end{array}$} & \multirow[t]{2}{*}{ MGUS } & \multicolumn{2}{|l|}{ Controls } \\
\hline & $\begin{array}{l}\text { With bone } \\
\text { disease }\end{array}$ & $\begin{array}{l}\text { Without bone } \\
\text { disease }\end{array}$ & & & $\begin{array}{l}\text { Patients with } \\
\text { non-neoplastic } \\
\text { disease }\end{array}$ & $\begin{array}{l}\text { Healthy- } \\
\text { donors }\end{array}$ \\
\hline Number of subjects & 58 & 22 & 16 & 35 & 10 & 30 \\
\hline Gender $(\mathrm{M} / \mathrm{F})$ & $30 / 28$ & $12 / 10$ & 9/7 & $18 / 17$ & $6 / 4$ & $18 / 12$ \\
\hline Median age (range) & $69(60-85)$ & $64(54-84)$ & $55(31-83)$ & $60(29-83)$ & $63(50-73)$ & $62(26-72)$ \\
\hline \multicolumn{7}{|l|}{$\begin{array}{l}\text { Monoclonal } \\
\text { Component: }\end{array}$} \\
\hline $\mathrm{IgG} / \mathrm{IgA} / \mathrm{BJ} / \mathrm{IgD} / \mathrm{NS}$ & $47-8-2-1-0$ & $18-3-1-0-0$ & & $25-10-0-0-0$ & - & - \\
\hline \multirow[t]{3}{*}{ ISS-stage } & ISS-1: 20 & ISS-1: 11 & & & & \\
\hline & ISS-2: 18 & ISS-2: 6 & & & & \\
\hline & ISS-3: 20 & ISS-3: 5 & & & & \\
\hline $\mathrm{Hb}<10 \mathrm{~g} / \mathrm{dL}$ & 12 & 5 & & - & & - \\
\hline Creatinine $\geq 2 \mathrm{mg} / \mathrm{dl}$ & 5 & 4 & & - & & - \\
\hline Albumin $<3.5 \mathrm{~g} / \mathrm{dL}$ & 15 & 2 & & - & & - \\
\hline$\beta 2-\mathrm{M}>3 \mathrm{mg} / \mathrm{L}$ & 8 & 2 & & - & & - \\
\hline$\beta 2-\mathrm{M}>6 \mathrm{mg} / \mathrm{L}$ & 7 & & & - & & - \\
\hline $\mathrm{LDH}>240 \mathrm{U} / \mathrm{L}$ & 4 & 1 & & - & & - \\
\hline Calcium > $10 \mathrm{mg} / \mathrm{dl}$ & - & & & - & & - \\
\hline
\end{tabular}

Abbreviation: MM, multiple myeloma; MGUS, monoclonal gammopathy of undetermined significance; M, male; F, female; Ig, immunoglobulin; Hb, hemoglobin; CRP, C-reactive protein; LDH, lactate deydrogenase; ISS, International Staging System; NS, non secretory.

supplemented with $10 \%$ FBS and cultured in the absence or presence of anti-LIGHT mAb $(0.005$ to $500 \mathrm{ng} / \mathrm{ml}$; R\&D Systems Inc., Minneapolis, MN) or control antiimmunoglobulin $\mathrm{G}(\mathrm{IgG})-\mathrm{Ab}$. PBMCs and purified CD14+ cells from healthy-donors were cultured in the presence or absence of $25 \mathrm{ng} / \mathrm{ml}$ recombinant human Macrophage Colony Stimulating Factor (rh-MCSF) plus either $30 \mathrm{ng} / \mathrm{ml} \mathrm{rh}-\mathrm{RANKL}$ or rh-LIGHT (range $0-50 \mathrm{ng} / \mathrm{ml}$ ) (all from R\&D Systems). For some experiments, PBMC and CD14+ cell cultures were treated with MCSF $(25 \mathrm{ng} / \mathrm{ml})$, RANKL (20 ng/ml), and/or LIGHT (range $5-50 \mathrm{ng} / \mathrm{ml}$ ). Mature OCs were identified as Tartrate-Resistant Acid Phosphatase (Sigma) positive (TRAP+) cells containing 3 or more nuclei. OC resorbing activity was assessed by plating the cells on Millennium multiwell slides (Millennium Biologix, Kingston, ON, Canada).

To study the phophorylation of IkB, JNK and AKT, healthy-donor PBMCs were cultured for 10 days in the presence of MCSF to obtain pre-osteoclasts, that after overnight starvation were incubated with RANKL, RANKL + LIGHT, or LIGHT over a time course (0 to $60 \mathrm{~min}$ ).

\section{Osteoblastogenesis}

BMNCs were plated at $4 \times 10^{5} / \mathrm{cm}^{2}$ in osteogenic differentiating medium [a-MEM supplemented with $10 \%$ FBS, $50 \mu \mathrm{g} / \mathrm{mL}$ ascorbic acid, $10^{-8} \mathrm{M}$ dexamethasone and $10 \mathrm{mM}$ beta-glycerophosphate (Sigma)]. BMNCs from patients without bone disease were cultured in the presence or absence of rh-LIGHT (range 20-100 ng/ml). Conversely, BMNCs from MM-bone disease patients were cultured in the absence or presence of 100 and $200 \mathrm{ng} /$ $\mathrm{ml}$ neutralizing anti-LIGHT $\mathrm{mAb}$ or control anti-IgG Ab. After 21 days, colony forming unit-fibroblast (CFU-F) formation was assessed with alkaline phosphatase (ALP, Sigma) staining. After 30 days, in parallel cultures CFU-OB formation was assessed with Von Kossa staining [8]. The mRNA expression of ALP, collagen-I (COLL-I), Fra-2 and JunD was analyzed in CFU-F cultures, and that of osteopontin (OPN), Osterix (OSX), bone sialoprotein II (BSP II) and osteocalcin (OCN) in CFU-OB cultures.

BMSCs, cultured in a-MEM with $10 \%$ FBS, after reaching confluence, were seeded in 6-well plate at 
$100000 /$ well and cultured in osteogenic medium for 0,10 and 20 days. At each time, RNA was extracted to evaluate LIGHT expression.

MSCs, seeded in 24-well-plate at 400/well, were cultured alone for 8 days in osteogenic differentiating medium, in the absence or presence of $100 \mathrm{ng} / \mathrm{ml} \mathrm{LIGHT}$ and/or anti-sclerostin mAb (R\&D Systems). In the same conditions, MSCs were also co-cultured with monocytes alone, T-cells alone or monocytes plus T-cells at 750000 cell/well, respectively. At the end of culture period, ALP staining or mRNA extraction were performed to evaluate ALP and COLL-I expression.

\section{Immunohistochemistry}

BM biopsies were fixed in $4 \%$ neutral buffered formalin solution, decalcified, paraffin-embedded, and cut into $5 \mu \mathrm{m}$ slices. After standard antigen retrieval procedures, the sections were incubated overnight at $4^{\circ} \mathrm{C}$ with primary mouse anti-human LIGHT (Abcam, Cambridge Science Park). The reaction was revealed with Dako EnVision ${ }^{\mathrm{TM}}$ FLEX+ detection system (Dako Italia S.p.A. Milan, Italy).

\section{Flow cytometry analysis}

Freshly BM and PB samples were stained with suitable conjugated antibody: PE-LIGHT (R\&D Systems), CD45-APC-Cy7, FITC-CD8, FITC-CD4, Pe-Cy-5-CD14 and FITC-CD16 (Becton Dickinson, Milan, Italy). Flow cytometry analysis was performed on a FACSCantoTM II or BD AccuriTM C6 flow cytometer (Becton Dickinson Immunocytometry System, Mountain View, CA, USA). Positivity area was determined using an isotype-matched $\mathrm{mAb}$, and a total of 2000 events for each cell sub-population was acquired.

\section{RNA isolation and real-time polymerase chain reaction (PCR) amplification}

RNA extraction and reverse-transcription as well as Real-Time PCR amplification were performed, as previously described [12]. The appropriate primer pairs were listed in Table 3.

\section{Western blot analysis}

Cell protein extracts were analyzed by western blotting, as previously described [12]. The following primary antibodies were used: anti-LIGHT and anti- $\beta$-actin (Santa Cruz Biotechnology, Santa Cruz, CA), anti-pAKT, anti-pIkB, anti-pJNK, anti-total AKT, antiIkB, anti-total-ERK and anti-total JNK (Cell Signaling, San Diego, CA, USA).

\section{Cell proliferation assay}

After 10 days of culture, the anti-LIGHT effect on BMNC proliferation was evaluated with BrdU incorporation by using a cell proliferation enzyme-linked immunosorbent assay (ELISA) kit (Roche Diagnostics, Mannheim, Germany) according to the manufacturer's instructions.

Table 3: Sense and antisense primer sequences.

\begin{tabular}{|c|c|c|c|}
\hline Gene & Sense primer & Antisense primer & Accession number \\
\hline LIGHT & 5' CAGTGTTTGTGGTGGATGG 3' & 5' GGGTTGACCTCGTGAGAC & NM_003807.3 \\
\hline ALP & 5' CGCACGGAACTCCTGACC 3' & 5' GCCACCACCACCATCTCG 3' & NM_000478.4 \\
\hline COLL 1 & 5' CGTGGCAGTGATGGAAGTG 3' & 5' AGCAGGACCAGCGTTACC 3' & NM_000089.3 \\
\hline $\mathrm{OCN}$ & 5' ACACTCCTCGCCCTATTG 3' & 5' CAGCCATTGATACAGGTAGC 3' & NM_199173.4 \\
\hline BSP II & 5' CTGCTACAACACTGGGCTATG 3' & 5' ТТССТТССТСТТССТССТСТТС 3' & NM_004967.3 \\
\hline OSX & 5' GCAAGGTGTATGGCAAGG 3' & 5' CATCCGAACGAGTGAACC 3' & NM_001173467.1 \\
\hline Fra-2 & 5' GAACCTCGTCTTCACCTATCC 3' & 5' CCGCTGCTACTGCTTCTG 3' & NM_005253.3 \\
\hline Jun-D & 5' CTCATCATCCAGTCCAAC 3' & 5' GTTCTGCTTGTGTAAATCC 3' & NM_001286968.1 \\
\hline OPN & 5' CTGATGAATCTGATGAACTGGTC 3' & 5' GTGATGTCCTCGTCTGTAGC 3' & NM_001251830.1 \\
\hline Sclerostin & 5' CAGCCTTCCGTGTAGTGG 3' & 5' TTCATGGTCTTGTTGTTCTCC 3' & NM_025237.2 \\
\hline$\beta$-Actin & 5' AATCGTGCGTGACATTAAG 3' & 5' GAAGGAAGGCTGGAAGAG 3' & NM_001101.3 \\
\hline
\end{tabular}

Abbreviation: ALP, Alkaline Phosphatase; COLL I, Collagen Type I; OCN, Osteocalcin; BSP II, Bone Sialoprotein; OSX, Osterix; OPN, Osteopontin. 


\section{ELISA}

Patient and control sera as well as media from BMNC, PBMC and BMMNC cultures, were evaluated for LIGHT by ELISA (R\&D Systems) according to manufacturer's instructions. The results were expressed as mean \pm standard error (SE).

\section{Statistical analyses}

Statistical analyses were performed by ANOVA or Student's t-test with the Statistical Package for the Social Sciences (spssx/pc) software (SPSS, Chicago, IL, USA). The results were considered statistically significant for $p<0.05$.

\section{ACKNOWLEDGEMENTS}

The authors thank Ministero dell'Istruzione Università e Ricerca (ex 60\% grant to Maria Grano) and Associazione Italiana per la Ricerca sul Cancro (AIRC, Grant no. IG_11957 to Maria Grano). The authors thanks Pasqua Bellocci for technical support.

\section{Conflict of interest statement}

The authors declare no conflict of interest.

\section{REFERENCES}

1. Kyle RA, Rajkumar SV. Criteria for diagnosis, staging, risk stratification and response assessment of multiple myeloma. Leukemia. 2009; 23:3-9.

2. Oranger A, Carbone C, Izzo M, Grano M. Cellular mechanisms of multiple myeloma bone disease. Clin Dev Immunol. 2013; 2013:289458.

3. Garcia-Gomez A, De Las Rivas J, Ocio EM, Díaz-Rodríguez E, Montero JC, Martín M, Blanco JF, Sanchez-Guijo FM, Pandiella A, San Miguel JF, Garayoa M. Transcriptomic profile induced in bone marrow mesenchymal stromal cells after interaction with multiple myeloma cells: implications in myeloma progression and myeloma bone disease. Oncotarget. 2014; 5:8284-8305.

4. Demchenko YN, Kuehl WM. A critical role for the NFkB pathway in multiple myeloma. Oncotarget. 2010; 1:59-68.

5. Oshima T, Abe M, Asano J, Hara T, Kitazoe K, Sekimoto E, Tanaka Y, Shibata H, Hashimoto T, Ozaki S, Kido S, Inoue D, Matsumoto T. Myeloma cells suppressed bone formation by secreting a soluble Wnt inhibitor, sFRP-2. Blood. 2005; 106:3160-3165.

6. Wang XT, He YC, Zhou SY, Jiang JZ, Huang YM, Liang YZ, Lai YR. Bone marrow plasma macrophage inflammatory protein protein-1 alpha (MIP-1 alpha) and sclerostin in multiple myeloma: Relationship with bone disease and clinical characteristics. Leuk Res. 2014; 38:525-531.

7. Brunetti G, Oranger A, Mori G, Specchia G, Rinaldi E, Curci P, Zallone A, Rizzi R, Grano M, Colucci S. Sclerostin is overexpressed by plasma cells from multiple myeloma patients. Ann N Y Acad Sci. 2011; 1237:19-23.

8. Colucci S, Brunetti G, Oranger A, Mori G, Sardone F, Specchia G, Rinaldi E, Curci P, Liso V, Passeri G, Zallone A, Rizzi R, Grano M. Myeloma cells suppress osteoblasts through sclerostin secretion. Blood Cancer J. 1,e27; 2011.

9. Terpos E, Christoulas D, Katodritou E, Bratengeier C, Gkotzamanidou M, Michalis E, Delimpasi S, Pouli A, Meletis J, Kastritis E, Zervas K, Dimopoulos MA. Elevated circulating sclerostin correlates with advanced disease features and abnormal bone remodeling in symptomatic myeloma: reduction post-bortezomib monotherapy. Int $\mathrm{J}$ Cancer. 2012; 131:1466-1471.

10. Kristensen IB, Christensen JH, Lyng MB, Møller MB, Pedersen L, Rasmussen LM, Ditzel HJ, Abildgaard N. Expression of osteoblast and osteoclast regulatory genes in the bone marrow microenvironment in multiple myeloma: only up-regulation of Wnt inhibitors SFRP3 and DKK1 is associated with lytic bone disease. Leuk Lymphoma. 2014; 55:911-919.

11. Tian E, Zhan F, Walker R, Rasmussen E, Ma Y, Barlogie B, Shaughnessy JD Jr. The role of the Wnt-signaling antagonist DKK1 in the development of osteolytic lesions in multiple myeloma. N Engl J Med. 2003; 349:2483-2494.

12. Colucci S, Brunetti G, Rizzi R, Zonno A, Mori G, Colaianni G, Del Prete D, Faccio R, Liso A, Capalbo S, Liso V, Zallone A, Grano M. T cells support osteoclastogenesis in an in vitro model derived from human multiple myeloma bone disease: the role of the OPG/TRAIL interaction. Blood. 2004; 104:3722-3730.

13. Giuliani N, Colla S, Sala R, Moroni M, Lazzaretti M, La Monica S, Bonomini S, Hojden M, Sammarelli G, Barillè S, Bataille R, Rizzoli V. Human myeloma cells stimulate the receptor activator of nuclear factorkappa B ligand (RANKL) in T lymphocytes: a potential role in multiple myeloma bone disease. Blood. 2002; 100:4615-4621.

14. Colucci S, Brunetti G, Mori G, Oranger A, Centonze M, Mori C, Cantatore FP, Tamma R, Rizzi R, Liso V, Zallone A, Grano M. Soluble decoy receptor 3 modulates the survival and formation of osteoclasts from multiple myeloma bone disease patients. Leukemia. 2009; 23:2139-2146.

15. Mauri DN, Ebner R, Montgomery RI, Kochel KD, Cheung TC, Yu GL, Ruben S, Murphy M, Eisenberg RJ, Cohen GH, Spear PG, Ware CF. LIGHT, a new member of the TNF superfamily, and lymphotoxin a are ligands for herpesvirus entry mediator. Immunity. 1998; 8:21-30. 
16. Tamada K, Shimozaki K, Chapoval AI, Zhai Y, Su J, Chen SF, Hsieh SL, Nagata S, Ni J, Chen L. LIGHT, a TNF-like molecule, costimulates $\mathrm{T}$ cell proliferation and is required for dendritic cell-mediated allogeneic $\mathrm{T}$ cell response. J Immunol. 2000; 164:4105-4110.

17. Harrop JA, Reddy $M$, Dede $K$, Brigham-Burke $M$, Lyn S, Tan KB, Silverman C, Eichman C, DiPrinzio R, Spampanato J, Porter T, Holmes S, Young PR, Truneh A. Antibodies to TR2 (herpesvirus entry mediator), a new member of the TNF receptor superfamily, block T cell proliferation, expression of activation markers, and production of cytokines. J Immunol. 1998; 161:1786-1794.

18. Kwon BS, Tan KB, Ni J, Oh KO, Lee ZH, Kim KK, Kim YJ, Wang S, Gentz R, Yu GL, Harrop J, Lyn SD, Silverman C, Porter TG, Truneh A, Young PR. A newly identified member of the tumor necrosis factor receptor superfamily with a wide tissue distribution and involvement in lymphocyte activation. J Biol Chem. 1997; 272:14272-14276.

19. Browning JL, Miatkowski K, Sizing I, Griffiths D, Zafari M, Benjamin CD, Meier W, Mackay F. Signaling through the lymphotoxin $\beta$ receptor induces the death of some adenocarcinoma tumor lines. J Exp Med. 1996; 183:867-878

20. Harrop JA, McDonnell PC, Brigham-Burke M, Lyn SD, Minton J, Tan KB, Dede K, Spampanato J, Silverman C, Hensley P, DiPrinzio R, Emery JG, Deen K, Eichman C, Chabot-Fletcher M, Truneh A, Young PR. Herpesvirus entry mediator ligand (HVEM-L), a novel ligand for HVEM/TR2, stimulates proliferation of T cells and inhibits HT29 cell growth. J Biol Chem. 1998; 273:27548-27556.

21. Hsu H1, Solovyev I, Colombero A, Elliott R, Kelley M, Boyle WJ. ATAR, a novel tumor necrosis factor receptor family member, signals through TRAF2 and TRAF5. J Biol Chem. 1997; 272:13471-13474.

22. Marsters SA1, Ayres TM, Skubatch M, Gray CL, Rothe M, Ashkenazi A. Herpesvirus entry mediator, a member of the tumor necrosis factor receptor (TNFR) family, interacts with members of the TNFR-associated factor family and activates the transcription factors NF-kappaB and AP-1. J Biol Chem. 1997; 272:14029-14032.

23. Arch RH1, Gedrich RW, Thompson CB. Tumor necrosis factor receptor-associated factors (TRAFs) - a family of adapter proteins that regulates life and death. Genes Dev. 1998; 12:2821-2830.

24. Zhai Y, Guo R, Hsu TL, Yu GL, Ni J, Kwon BS, Jiang GW, Lu J, Tan J, Ugustus M, Carter K, Rojas L, Zhu F, Lincoln C, Endress G, Xing L, Wang S, Oh KO, Gentz R, Ruben S, Lippman ME, Hsieh SL, Yang D. LIGHT, a novel ligand for lymphotoxin beta receptor and TR2/HVEM induces apoptosis and suppresses in vivo tumor formation via gene transfer. J Clin Invest. 1998; 102:1142-1151.
25. Rooney IA, Butrovich KD, Glass AA, Borboroglu S, Benedict CA, Whitbeck JC, Cohen GH, Eisenberg RJ, Ware CF. The lymphotoxin-beta receptor is necessary and sufficient for LIGHT-mediated apoptosis of tumor cells. J Biol Chem. 2000; 275:14307-14315.

26. Granger SW, Rickert S. LIGHT-HVEM signaling and the regulation of T cell-mediated immunity. Cytokine Growth Factor Rev. 2003; 14:289-296.

27. Tamada K, Shimozaki K, Chapoval AI, Zhu G, Sica G, Flies D, Boone T, Hsu H, Fu YX, Nagata S, Ni J, Chen L. Modulation of T-cell-mediated immunity in tumor and graft-versus-host disease models through the LIGHT co-stimulatory pathway. Nat Med. 2000; 6:283-289.

28. Shaikh RB, Santee S, Granger SW, Butrovich K, Cheung T, Kronenberg M, et al. Constitutive expression of LIGHT on $\mathrm{T}$ cells leads to lymphocyte activation, inflammation, and tissue destruction. J Immunol. 2001; 167:6330-6337.

29. Wang J, Lo JC, Foster A, Yu P, Chen HM, Wang Y, Tamada K, Chen L, Fu YX. The regulation of $\mathrm{T}$ cell homeostasis and autoimmunity by $\mathrm{T}$ cell-derived LIGHT. J Clin Invest. 2001; 108:1771-1780.

30. Ishida $\mathrm{S}$, Yamane $\mathrm{S}$, Nakano $\mathrm{S}$, Yanagimoto $\mathrm{T}$, Hanamoto Y, Maeda-Tanimura M, Toyosaki-Maeda T, Ishizaki J, Matsuo Y, Fukui N, Itoh T, Ochi T, Suzuki R. The interaction of monocytes with rheumatoid synovial cells is a key step in LIGHT-mediated inflammatory bone destruction. Immunology. 2009; 128:e315-e324.

31. Edwards JR, Sun SG, Locklin R, Shipman CM, Adamopoulos IE, Athanasou NA, Sabokbar A. LIGHT (TNFSF14), a novel mediator of bone resorption, is elevated in rheumatoid arthritis. Arthritis Rheum. 2006; 54:1451-1462.

32. Hemingway F, Kashima TG, Knowles HJ, Athanasou NA. Investigation of osteoclastogenic signalling of the RANKL substitute LIGHT. Exp Mol Pathol. 2013; 94: 380-385.

33. Baksh D, Davies JE, Zandstra PW. Soluble factor cross-talk between human bone marrow-derived hematopoietic and mesenchymal cells enhances in vitro CFU-F and CFU-O growth and reveals heterogeneity in the mesenchymal progenitor cell compartment. Blood. 2005; 106:3012-3019.

34. van Bezooijen RL, ten Dijke P, Papapoulos SE, Löwik CW. SOST/sclerostin, an osteocyte-derived negative regulator of bone formation. Cytokine Growth Factor Rev. 2005; 16:319-327.

35. Pierer M, Brentano F, Rethage J, Wagner U, Hantzschel H, Gay RE, Gay S, Kyburz D. The TNF superfamily member LIGHT contributes to survival and activation of synovial fibroblasts in rheumatoid arthritis. Rheumatology (Oxford). 2007; 46:1063-1070. 
36. Kang YM, Kim SY, Kang JH, Han SW, Nam EJ, Kyung HS, Park JY, Kim IS. LIGHT up-regulated on B lymphocytes and monocytes in rheumatoid arthritis mediates cellular adhesion and metalloproteinase production by synoviocytes. Arthritis Rheum. 2007; 56:1106-1117.

37. Giuliani N, Lisignoli G, Colla S, Lazzaretti M, Storti P, Mancini C, Bonomini S, Manferdini C, Codeluppi K, Facchini A, Rizzoli V. CC-Chemokine ligand 20/macrophage inflammatory protein-3alpha and CC-chemokine receptor 6 are overexpressed in myeloma microenvironment related to osteolytic bone lesions. Cancer Res. 2008; 68:6840-6850.

38. El Hajj Dib I, Me'lanie G, Valery S, Romuald M, Michel B, Kamel S. Multiple myeloma cells directly stimulate bone resorption in vitro by down-regulating mature osteoclast apoptosis. Leuk Res. 2008; 2:1279-1287.

39. Boyle WJ, Simonet WS, Lacey DL. Osteoclast differentiation and activation. Nature. 2003; 423:337-342.

40. Wong BR, Besser D, Kim N, Arron JR, Vologodskaia M, Hanafusa H, Choi Y. TRANCE, a TNF family member, activates Akt/PKB through a signaling complex involving TRAF6 and c-Src. Mol Cell. 1999; 4:1041-1049.

41. Kido S, Inoue D, Hiura K, Javier W, Ito Y, Matsumoto T. Expression of RANK is dependent upon differentiation into the macrophage/osteoclast lineage: induction by 1alpha, 25-dihydroxyvitamin D3 and TPA in a human myelomonocytic cell line, HL60. Bone. 2003; 32: 621-629.

42. Pearse RN, Sordillo EM, Yaccoby S, Wong BR, Liau DF, Colman N, Michaeli J, Epstein J, Choi Y. Multiple myeloma disrupts the TRANCE/ osteoprotegerin cytokine axis to trigger bone destruction and promote tumor progression. Proc Natl Acad Sci U S A. 2001; 98: 11581-11586.

43. Yao S, Pan F, Prpic V, Wise GE. Differentiation of stem cells in the dental follicle. J Dent Res. 2008; 87:767-771.

44. Ota K, Quint P, Ruan M, Pederson L, Westendorf JJ, Khosla S, Oursler MJ. Sclerostin is expressed in osteoclasts from aged mice and reduces osteoclastmediated stimulation of mineralization. J Cell Biochem. 2013; 114:1901-1907.

45. Kusu N, Laurikkala J, Imanishi M, Usui H, Konishi M, Miyake A, Thesleff I, Itoh N. Sclerostin is a novel secreted osteoclast-derived bone morphogenetic protein antagonist with unique ligand specificity. J Biol Chem. 2003; 278:24113-24117.

46. Jung Y, Song J, Shiozawa Y, Wang J, Wang Z, Williams B, Havens A, Schneider A, Ge C, Franceschi RT, McCauley LK, Krebsbach PH, Taichman RS. Hematopoietic stem cells regulate mesenchymal stromal cell induction into osteoblasts thereby participating in the formation of the stem cell niche. Stem Cells. 2008; 26:2042-2051.
47. Chang MK, Raggatt LJ, Alexander KA, Kuliwaba JS, Fazzalari NL, Schroder K, Maylin ER, Ripoll VM, Hume DA, Pettit AR. Osteal tissue macrophages are intercalated throughout human and mouse bone lining tissues and regulate osteoblast function in vitro and in vivo. J Immunol. 2008; 181:1232-1244.

48. Alexander KA, Chang MK, Maylin ER, Kohler T, Muller R, Wu AC, Van Rooijen N, Sweet MJ, Hume DA, Raggatt LJ, Pettit AR. Osteal macrophages promote in vivo intramembranous bone healing in a mouse tibial injury model. J Bone Miner Res. 2011; 26:1517-1532.

49. Groh ME, Maitra B, Szekely E, Koc ON. Human mesenchymal stem cells require monocyte-mediated activation to suppress alloreactive T cells. Exp Hematol. 2005; 33:928-934.

50. Aggarwal S, Pittenger MF. Human mesenchymal stem cells modulate allogeneic immune cell responses. Blood. 2005; 105:1815-1822.

51. Nemeth K, Leelahavanichkul A, Yuen PS, Mayer B, Parmelee A, Doi K, Robey PG, Leelahavanichkul K, Koller BH, Brown JM, Hu X, Jelinek I, Star RA, Mezey E. Bone marrow stromal cells attenuate sepsis via prostaglandin $\mathrm{E}(2)$-dependent reprogramming of host macrophages to increase their interleukin-10 production. Nat Med. 2009; 15:42-49.

52. Beyth S, Borovsky Z, Mevorach D, Liebergall M, Gazit Z, Aslan H, Galun E, Rachmilewitz J. Human mesenchymal stem cells alter antigen-presenting cell maturation and induce T-cell unresponsiveness. Blood. 2005; 105:2214-2219.

53. Kim J, Hematti P. Mesenchymal stem cell-educated macrophages: a novel type of alternatively activated macrophages. Exp Hematol. 2009; 37:1445-1453.

54. Bellido T, Borba VZ, Roberson P, Manolagas SC. Activation of the Janus kinase/STAT (signal transducer and activator of transcription) signal transduction pathway by interleukin-6-type cytokines promotes osteoblast differentiation. Endocrinology. 1997; 138:3666-3676.

55. Nishimura R, Moriyama K, Yasukawa K, Mundy GR, Yoneda T. Combination of interleukin- 6 and soluble interleukin-6 receptors induces differentiation and activation of JAK-STAT and MAP kinase pathways in MG-63 human osteoblastic cells. J Bone Miner Res. 1998; 13:777-785.

56. Nicolaidou V1, Wong MM, Redpath AN, Ersek A, Baban DF, Williams LM, Cope AP, Horwood NJ. Monocytes induce STAT3 activation in human mesenchymal stem cells to promote osteoblast formation. PLoS One. 2012; 7:e39871.

57. International Myeloma Working Group Criteria for the classification of monoclonal gammopathies, multiple myeloma and related disorders: a report of the 
International Myeloma Working Group. Br J Haematol. 2003; 121:749-757.

58. Greipp PR, San Miguel J, Durie BG, Crowley JJ, Barlogie B, Bladé J, Boccadoro M, Child JA, Avet-Loiseau H, Kyle RA, Lahuerta JJ, Ludwig H, Morgan G, Powles R, Shimizu K, Shustik C, Sonneveld P, Tosi P, Turesson I, Westin J. International staging system for multiple myeloma. J Clin Oncol. 2005; 23:3412-3420.

59. Mori G, Ballini A, Carbone C, Oranger A, Brunetti G, Di Benedetto A, Rapone B, Cantore S, Di Comite M,
Colucci S, Grano M, Grassi FR. Osteogenic differentiation of dental follicle stem cells. Int J Med Sci. 2012; 9:480-487.

60. Brunetti G, Faienza MF, Piacente L, Ventura A, Oranger A, Carbone C, Di Benedetto A, Colaianni G, Gigante M, Mori G, Gesualdo L, Colucci S, Cavallo L, Grano M. High dickkopf-1 levels in sera and leukocytes from children with 21-hydroxylase deficiency on chronic glucocorticoid treatment. Am J Physiol Endocrinol Metab. 2013; 304:E546-E554. 